\title{
ANÁLISE ESPAÇO-TEMPORAL DE FOCOS DE CALOR NA ÁREA DE PROTEÇÃO AMBIENTAL DO MARAJÓ
}

\section{ANÁLISIS TEMPORAL DE ENFOQUE DE CALOR EN EL ÁREA DE PROTECCIÓN AMBIENTAL DE MARAJÓ}

\section{TEMPORAL HEAT FOCUS ANALYSIS AT MARAJÓ ENVIRONMENTAL PROTECTION AREA}

\begin{abstract}
Heloise de Sousa Castro ${ }^{1}$; Eduarda Emilia Magalhães Cristóvão ${ }^{2}$; Ingrid Leão Campos ${ }^{3}$; Wenderson Holanda de Oliveira ${ }^{4}$; Breno Pinto Rayol ${ }^{5}$
\end{abstract}

DOI: https://doi.org/10.31692/978-65-991061-4-9.151-156

\section{INTRODUÇÃO}

A descoberta do fogo nos primórdios da humanidade mudou o curso, forma de interação e sobrevivência da nossa espécie, principalmente ao se falar de agricultura. Sinônimo de praticidade para limpeza de área, fertilidade gratuita e baixo custo de aplicação é utilizado amplamente por produtores de grande ou pequeno porte. Destaca-se a estreita relação da silvicultura com o uso do fogo, enfatizando que mesmo adotando práticas de controle é comum ocorrer descontrole na queima o que pode acarretar a incêndios florestais de grande proporção (SOARES \& BATISTA in apud, 2007).

Assim, há uma linha tênue entre vantagens e desvantagens da utilização do fogo no campo. O novo código florestal (2012), permite o uso desta técnica em determinadas situações, como em áreas de práticas agropastoris e florestais mediante um planejamento específico e aprovação do Sistema Nacional do Meio Ambiente (SISNAMA). A análise prévia de acordo com o bioma, biodiversidade e atividades ocorridas no espaço onde se deseja fazer uso do fogo devem ser levadas em consideração para evitar acidentes e imprevistos. Nesse contexto, aplica-se o estudo de análise espaço-temporal que é ferramenta de grande suporte para aplicação de variadas técnicas na agricultura e em outras áreas.

Dentre as problemáticas relevantes em se tratando de monitoramento, prevenção e proteção florestal e a extensão do território nacional que dificulta ações mais incisivas. Dos biomas presentes que se destacam em nosso país está a Amazônia, sua vastidão a torna vulnerável ultrapassando fronteiras nacionais que podem dificultar as ações de combate (LIMA, 2018). Portanto, objetivou-se analisar as possíveis causas da ocorrência de focos de

\footnotetext{
${ }^{1}$ Engenharia florestal, Universidade Federal Rural da Amazônia, heloise_castro14@hotmail.com

${ }^{2}$ Engenharia florestal, Universidade Federal Rural da Amazônia, eduardamaga30@ gmail.com

${ }^{3}$ Engenharia Florestal, Universidade Federal Rural da Amazônia, milenaa.santoss@ outlook.com

${ }^{4}$ Engenharia Florestal, Universidade Federal Rural da Amazônia, whowenderson@ gmail.com

${ }^{5}$ Professor adjunto, Universidade Federal Rural da Amazônia, bprayol@yahoo.com.br
} 
calor na área de proteção ambiental do Marajó através do estudo espaço-temporal.

\section{FUNDAMENTAÇÃO TEÓRICA}

Segundo a Secretaria de Meio Ambiente do Pará (2008), o Estado é de grande expressividade em se tratando de queimadas e focos de calor tendo em vista sua extensão e o pouco serviço florestal, se relacionarmos dimensão territorial e número de prestadores de serviço. Assim, áreas de proteção ambiental (APA), como a do Marajó, sofrem com índices exacerbados de queimadas e focos de calor, estes são caracterizados como uma das principais ameaças à manutenção de flora, fauna e economia local. Portanto, as queimadas podem ser objetos principais os quais coordenam a dinâmica social, econômica e ambiental ao entorno de onde ocorrem que compreende na Amazônia a agropecuária e atividades relacionadas (MORELLO, 2017). Como ferramenta de auxílio para esses casos está o estudo de análise espaço-temporal, com o qual é possível verificar as mudanças ocorridas dentro dos limites estabelecidos tentando compreender o modo como as relações acontecem dentro de determinada unidade societária levando em consideração aspectos sociais e culturais desses povos. Assim, torna-se imprescindível para tomadas de decisão e melhoria nas medidas estratégicas escolhidas para cada localidade (TOMZHINSKI, 2011).

\section{METODOLOGIA}

A APA do Marajó está localizada na mesorregião do Marajó que representa umas das mais ricas regiões do país em questão de recursos hídricos e biológicos, tendo destaque por ser formada por um conjunto de ilhas, que ao todo, representa a maior ilha flúvio marítima do mundo. Abrange uma área de 5.904.322ha, compreendendo 12 municípios e sendo considerada a maior Unidade de Conservação na costa norte do Brasil. A pluviosidade na mesorregião varia de $3100 \mathrm{~mm}$ na estação de Soure, na costa leste da ilha à 2500mm na região central, representada pelas estações de Cachoeira do Arari e Santa Cruz. O clima da região é caracterizado por dois períodos: a estação menos chuvosa, compreendida entre os meses de junho a novembro, e a estação mais chuvosa, com chuvas persistentes registradas todos os dias no período de dezembro a maio (LIMA et. al. 2004).

A quantificação de focos de calor foi realizada a partir de dados fornecidos pelo Instituto Nacional de Pesquisas Espaciais (INPE) através do Programa de Queimadas e estimadas utilizando sistema de informações geográficas, o software ArcMap 10.5. Foi considerada a divisão do ano em dois períodos (menos chuvoso e mais chuvoso), proposta por Lima et. al. (2004), a fim de verificar a relação entre quantidades de focos de calor e 
pluviosidade na região.

Objetivando analisar possíveis causas, utilizou-se dados de uso e ocupação do solo disponibilizados pelo programa TerraClass, que qualifica o desflorestamento na Amazônia Legal Brasileira, obtidos do mapeamento no ano de 2014 a partir das órbitas-ponto 223/60, 223/61, 224/60, 224/61, 225/60 e 225/61 do satélite Landsat 8 (sensor OLI), no Sistema de Projeção Lat/Long e Sistema Geodésico de Referência $S A D$ 69. Além disso, informações sobre a pluviosidade da região foram obtidos a partir do Instituto Nacional de Meteorologia (INMET) através do Banco de Dados Meteorológicos para Ensino e Pesquisa da estação de Soure.

\section{RESULTADOS E DISCUSSÃO}

Ao analisar os mapas de distribuição de focos de calor (Figura 1), pode-se verificar que estão distribuídos em maior parte em faixa litorânea, banhado pelas águas salgadas do Oceano Atlântico ao norte, pelas águas fluviais da foz do Rio Pará e Tocantins, ao sul. Em se tratando de uso e cobertura de solo da região do Arquipélago do Marajó, de acordo com os dados disponibilizados pelo programa TerraClass, os focos abrangem diferentes tipos de ambientes e estão concentrados principalmente em regiões de vegetação secundária com mosaico de ocupações e áreas de não florestas, todavia, abrange áreas de florestas nativas.

Figura 1: Mapa de distribuição de focos de calor para a região de estudo entre os anos de 2014 e 2018.
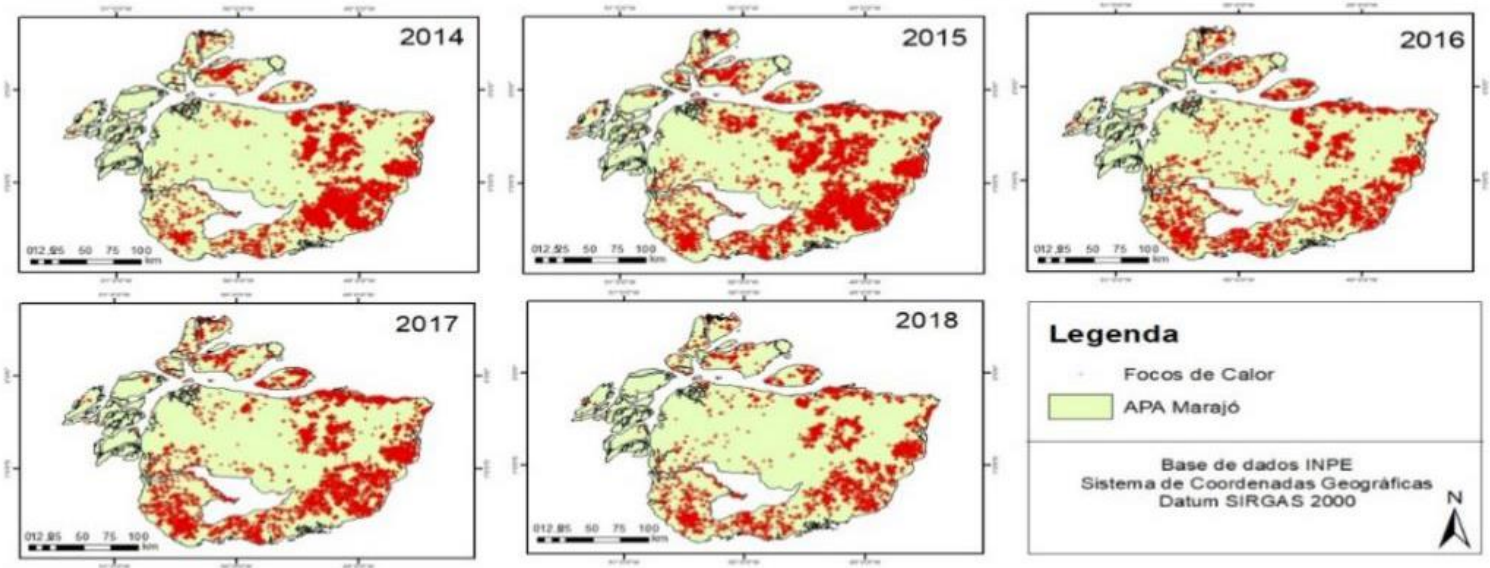

Fonte: Própria (2019)

Quanto a relação entre pluviosidade e quantidade de focos, nota-se que durante a estação mais chuvosa, culturalmente descrita como inverno amazônico, que compreende o período de dezembro a maio, é possível notar a redução no número de focos de calor, representando em média de $13,3 \%$ em relação ao total anual para a Unidade de Conservação. Todavia, apesar de dezembro ser considerado para efeito de estudo como parte 
da estação mais chuvosa, durante esse mês a média de focos de calor anual é de $968 \mathrm{~mm}$, cerca de $82,5 \%$ em relação ao total da estação, superior, por exemplo, a meses como agosto, que possui uma média anual de 343,4 focos de calor por ano (Figura 2).

FIGURA 2: Quantidade de focos de calor entre os anos de 2014 e 2018.

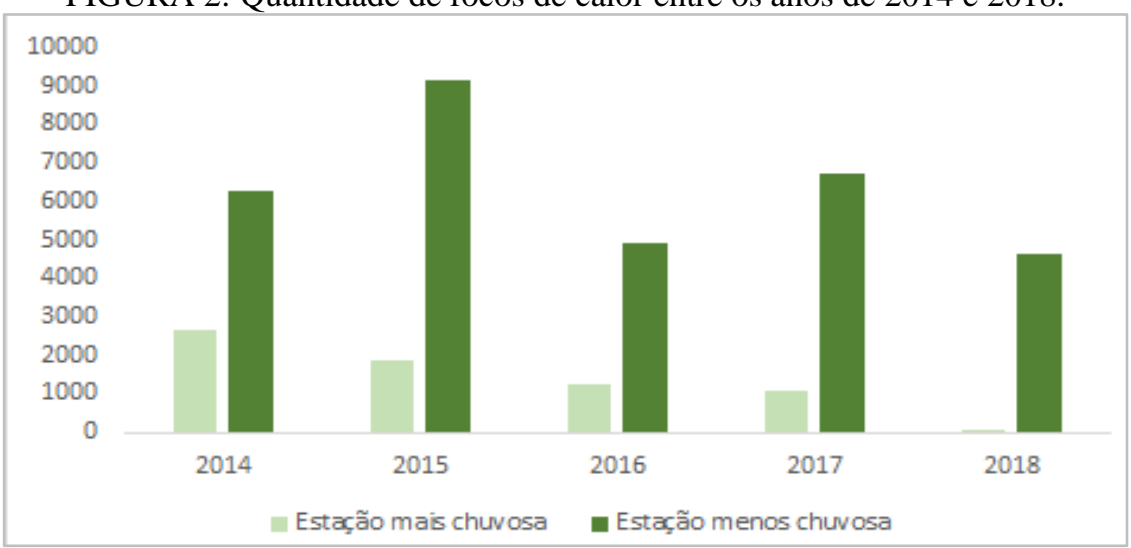

Fonte: Própria (2019).

De acordo com a Secretaria de Estado de Meio Ambiente e Sustentabilidade (SEMAS), houveram superávits pluviométricos registrados em maio de 2018, principalmente sobre áreas do Nordeste, Marajó, Região Metropolitana de Belém (RMB) e pequena parte do Sudoeste paraense. Esses superávits refletem na quantidade de focos de calor, uma vez que 2018 correspondeu ao ano com menor taxa de incidência. Segundo Homma et. al. (1992), há uma estreita relação entre os focos de calor e as formas de cultivo existentes na região. $\mathrm{O}$ modo de preparo do solo na região amazônica utiliza o processo de queima da vegetação como pré-plantio, isto garante uma fertilização gratuita, principalmente de potássio, se relacionada a outras medidas de cultivo. Deste modo, a expansão das fronteiras agrícolas é fator de extrema relevância nesta discussão.

O desenvolvimento na região aliado a baixa escolaridade e acesso a informação do homem rural amazônico associado a técnicas hereditárias com resultado a curto prazo, além de menos oneroso, formam o cenário no qual a queima é prática corriqueira. Quando o tamanho dos lotes não é expressivo, de modo que o que for produzido não supra as necessidades dos alocados, dá-se o esgotamento das áreas de florestas densas e, consequentemente, as capoeiras que já foram derrubadas pelo menos por 4 ou 5 vezes começam a apresentar problemas como a queda de produtividade das culturas (HOMMA, 1992).

Na Amazônia, em termos culturais, o aumento no número de dependentes por família exige o desmatamento de áreas maiores na busca de uma produção que garanta o nível mínimo de subsistência. Em se tratando de êxodo rural, áreas improdutivas podem ser tratadas 
como uma das principais causas deste acontecimento atrelada a isto está a falta de mão de obra no campo, o que pode justificar o uso de técnicas de mais fácil empregabilidade nos cultivos (PRATES, 2011).

\section{CONCLUSÕES}

É possível observar a existência de uma forte relação entre os focos de calor e pluviosidade na região da APA Marajó, além disso, a distribuição desses focos ocorre principalmente em regiões de não floresta e de vegetação secundária próximos a mosaicos de ocupação, entretanto, atinge também áreas de florestas estabelecidas. Vale ressaltar que a inserção de políticas públicas que possam, de fato, contribuir com o desenvolvimento das áreas rurais são de extrema importância nesse contexto.

\section{REFERÊNCIAS}

BRASIL. Plano de desenvolvimento territorial sustentável do arquipélago do Marajó. Casa Civil. 2006. Plano de desenvolvimento territorial sustentável do arquipélago do Marajó. Disponível em: <http://www.casacivil.gov.br/.arquivos/marajo.pdf> acesso em: jun. 2019.

FEARNSIDE, Philip M. Fogo e emissão de gases de efeito estufa dos ecossistemas florestais da Amazônia brasileira. Estudos avançados. v.16 n(44). 2002. Disponível em: <http://www.scielo.br/pdf/ea/v16n44/v16n44a07.pdf> acesso em: jun. 2019.

GONÇALVES, Karen dos Santos. CASTRO, Hermano Albuquerque de. HACON, Sandra de Souza. As queimadas na região amazônica e o adoecimento respiratório. Ciência \& Saúde Coletiva, 17(6):1523-1532, 2012. Disponível em: <http://www.scielo.br/pdf/csc/v17n6/v17n6a16.pdf> acesso em: jun. 2019.

HOMMA, Alfredo Kingo Oyama. WALKER, Robert T. SCALENA, Fredcrick N. CONTO, Amaldo José de. CARVALHO, Rui de Amorim. ROCHA; Antonio Carlos Paula Neves da. FERREIRA, Célio Armando Palheta. SANTOS, Antônio Itayguara Moreira dos. A dinâmica dos desmatamentos e das queimadas na Amazônia: uma análise microeconômica. Recursos naturais, ambiente e desenvolvimento sustentável. 1992. Disponível em: <https://ainfo.cnptia.embrapa.br/digital/bitstream/item/125066/1/DINAMICA-DOSDESMATAMENTOS.pdf> acesso em: jun.2019.

LIMA, A. M.M. OLIVEIRA, L.L. FONTINHAS, R.L. LIMA, J.S. Ilha do Marajó: histórica, hidroclimatologia, bacias hidrográficas e propostas de gestão. Holos environment. v.5. n.1, 2005- P. 65. ISSN: 1519-8634. Disponível em: <http://Users/Aluno\%2032.gnutecaHP/Desktop/331-1464-1-PB.pdf> acesso em: jun. 2019.

LIMA, Isabella Caixeta. Monitoramento dos focos de queimadas nos biomas Amazônia e Cerrado nas estações seca e chuvosa de 2017. Uberlândia-MG.2018. Trabalho de conclusão de curso. Disponível em: <https://repositorio.ufu.br/bitstream/123456789/22348/1/MonitoramentoFocosQueimadas.pdf 
> Acesso em: maio 2019.

Miranda, H. S.; Saito, C. H. \& Dias, B. F. S. 1996. Impactos de Queimadas em Áreas de Cerrado e Restinga. Departamento de Ecologia, Universidade de Brasília, 187p. Disponível em:

<http://www.pgecl.unb.br/images/sampledata/arquivos/teses/2000a2010/2007/Beatriz\%20Cas tro\%20Neves.pdf $>$. Acesso em: ago. 2019.

MORELLO, Thiago Fonseca. RAMOS, Rossano. STEIL, Lara. PARRY, Luke. BARLOW, Jos. MARKUSSON, Nils. FERREIRA, Amanda. Queimadas e incêndios florestais na Amazônia brasileira: por que as políticas públicas tem efeito limitado? Ambiente \& Sociedade. São Paulo. v. XX, n. 4 n p. 19-40 n out.-dez. 2017. Disponível em: <http://www.scielo.br/pdf/asoc/v20n4/pt_1809-4422-asoc-20-04-00019.pdf> Acesso em: jun. 2019.

NOVO código florestal. Curitiba: Sistema FAEP, 2012. Disponível em:<http://codigoflorestal.sistemafaep.org.br/wp-content/uploads/2012/11/novo-codigoflorestal.pdf>. Acesso em: ago. 2019.

PRATES, Rodolfo Coelho. BACHA, Carlos José Caetano. Os processos de desenvolvimento e desmatamento da Amazônia. Economia e Sociedade. Campinas. v. 20. n. 3 (43), p. 601-636, dez. 2011. Disponível em: <http://www.scielo.br/pdf/ecos/v20n3/a06v20n3.pdf> acesso em: jun. 2019.

Secretaria de Estado de Meio Ambiente. Área de preservação Arquipélago do Marajó. Disponível em: <https://uc.socioambiental.org/arp/1362> acesso em: jun. 2019.

SOARES, R. V.; BATISTA, A. C. Incêndios florestais: controle, efeitos e uso do fogo. Curitiba, 2007. 264p. In apud: SANTOS, Juliana Andressa Costa dos. PAULETTO, Daniella. MOTA, Cléo Gomes da. SILVA, Saulo Ubiratan Pinheiro da. NASCIMENTO, Gabriela de Cássia Santos do. GOMES, Vanessa de Sousa. Uso do fogo na agricultura: medidas preventivas e queima controlada no projeto de desenvolvimento sustentável Terra Nossa, Novo Progresso, Pará. Disponível em:<file:///C:/Users/ALUNO10/Downloads/5211-20750-1PB\%20(1).pdf>.Acesso em: ago. 2019.

TOMZHINSKI, Gustavo Wanderley. COURA, Pedro Henrique Ferreira. FERNANDES, Manoel do Couto. Avaliação da Detecção de Focos de Calor por Sensoriamento Remoto para o Parque Nacional do Itatiaia. Número Temático: Ecologia e Manejo de Fogo em Áreas Protegidas. Biodiversidade Brasileira (2011) Ano I, No 2, 201-211. Disponível em:< file:///C:/Users/User/Downloads/140-510-1-PB.pdf>. Acesso em: ago. 2019. 